The BMJ

Cite this as: $B M J 2022 ; 376: 0393$

http://dx.doi.org/10.1136/bmj.0393

Published: 15 February 2022

\title{
The gift of death
}

\section{Tessa Richards}

"I dreamed that I was dead last night. Then I woke up and found I was still here. It was such a disappointment."

My 98 year old mother surprised us with this comment, for she rarely talked about dying and death during her decline from advanced frailty, although she repeatedly said, "I never thought it would go on so long."

Her final months were harrowing to witness. But how much harder must they have been to bear? It's left me wondering if she, and we, her children, could have made any different decisions.

Ever well organised, she made end of life plans years before the event. These included listing who to bequeath her modest collection of precious things to, putting memorabilia in boxes that she thought her children and grandchildren would treasure, and choosing psalms, hymns, and music for her funeral. Her GP practice had her "Do not resuscitate" form. She had savings to pay for care.

Planning for death did not stop her enjoying life and enhancing the lives of others. She supported many elderly friends, most of whom she outlived.

Observation of their final journeys made her dread losing her independence and "lingering on" with poor quality of life. "If I get like that," she said, "you must take an axe to me."

Assisted dying is one of the topics addressed in the report of the Lancet Commission on the Value of Death: Bringing Death Back Into Life. ${ }^{12}$ Its headline message is that over medicalised "Western death systems" are in need of radical reform. It points the way to a "realistic utopia," where death is valued as a social and spiritual process, and families, communities, health and social care services care for the dying in partnership. The closest to the "ideal," a model of care in Kerala in India, is described. ${ }^{3}$ Regarding death as a physiological event to be hidden away, and a failure of modern medicine, damages people, and health systems alike.

At a recent webinar to launch the Lancet commissions' report, Raj Mani, an intensive care specialist in Yashoda Hospital, Ghaziabad, said that many people in India think high tech Western medicine is always the best form of care. As a result, too many people "die badly in intensive care units." Their suffering is "amplified" and the cost impoverishes their families. The report makes the same observation about some deaths during the covid-19 pandemic, and recommends that health systems prioritise management of suffering (not just extending life) and for all health and social care professionals to be competent to care for the dying and the bereaved.
In high income countries around $10 \%$ of total healthcare expenditure is spent on the last year of life, and "excessive" care exerts a notable toll on the environment as well as individuals and their families, said Richard Smith, co-chair of the commission. He also emphasised the gaping global inequity in access to palliative care services and opioids.

My mother was fortunate to have both. The challenge was to make her passage to death as smooth as possible.

\section{What counts as excessive treatment?}

When she presented with symptoms and signs of aortic stenosis at 80 , a doctor she saw told her "the good thing about this diagnosis is that when you die, you will die fast and won't suffer." Should she leave it at that? She asked us what we thought, listened to our varied views, and decided it was sensible to have a formal cardiac assessment. Tests revealed a critically tight stenosis and aortic valve replacement was recommended. She went ahead, and after a stormy postoperative course achieved a good quality of life.

Bilateral hip replacements followed. Then recurrent treatment for a combination of wet and dry macular degeneration. She bore the journey to near total blindness without complaint and systematically built a comprehensive support network which, stepped up over time, enabled her to live independently until she was 96.

Then grumbling abdominal symptoms reached a head. She was admitted to hospital with intestinal obstruction and found to have colon cancer. Aware this was a terminal diagnosis she asked about options and was given two. Move into the adjacent hospice to die or take a chance on colonic stenting. Risky, because of the site of the tumour, but if successful, should buy her a few more months.

She opted for the latter. My sister and I held her hands as she went down for the procedure exuding calm. She talked about having had a good innings, told the surgeon how grateful she was, and reassured him she fully understood the procedure may kill her. I suspect that was her wish.

It went well and she went to live in my brother and sister-in-laws lively household. Here a new community of support enabled her to find new things to enjoy. She did not complain about her deteriorating health and dutifully complied with her diet and treatment regimen.

Daily (aided) walks got shorter. She was pale and started to collapse. Anaemia due to bleeding from the cancer was suspected. Should a blood count be done? It was, and a blood transfusion rallied her for a bit. Her decline continued. Did covid vaccination 
make sense? Antibiotics for a chest infection? She had both.

Stairs became impossible. Weeks stretched to months over which her strength, memory, focus, and orientation ebbed away. She was tired, slept a lot, and stoically bore the indignity of needing help to use the commode, dress, and wash. Usually too tired to talk for long she still conjured bursts of sparkling exchange.

It was immeasurably sad to see her bed bound, increasingly deaf as well as blind, troubled by pain, oedematous hands and legs, sleeping badly, and experiencing loss of bowel control. Caring for her was physically, as well as emotionally, hard work and we sought the help of a live-in carer.

\section{The arrival of a death doula, was transformative}

A skilled South African carer came exuding warmth and good cheer. Looking after the dying "is my calling” she said, and I find it "hugely rewarding." She got my mother talking about her past and singing songs. They said prayers together and seized the best moments of the day. She speedily recognised the redoubtable spirit within my mother's pitifully wasted body and did not tip toe around dying and death.

A seasoned death doula, she accurately identified the day my mother would die and called the family to the bedside. After her death she opened the window to let her soul fly out. She bathed her and dressed her in clean clothes, with the same tenderness and respect she had always shown. The family found it harder to look death in the face. Happy to leave "practicalities" to the undertakers. Illustrating perhaps, one of the points made in the commission's report, about the disappearance of old rituals which honour the body of the dead.

Avoiding overmedicalisation at the end of life is challenging. At what age and stage is best high tech care neither appropriate or affordable? And who gets to make the decision? More open public, as well as professional, discussion and debate are needed, informed by better understanding of people's end of life experience, and what services and treatment they and those who care for them value. The opportunity costs of high healthcare spending in the last year of life are high and a balance to be struck between preferences of individuals and society as a whole.

My mother did not avoid dependency and did "linger on" longer than she wished. But caring for her at home brought the family together and thanks to her courage, patience, grace, and positivity there were happy times. I hope I can summon half of her resources when I'm dying-and secure the help of her death doula.

Competing interests: none declared

Provenance and peer review: commissioned, not peer reviewed

Sallnow L, Smith R, Ahmedzai SH, etalLancet Commission on the Value of Death. Report of the Lancet Commission on the Value of Death: bringing death back into life. Lancet 2022;S0140-6736(21)02314-X. doi: 10.1016/S0140-6736(21)02314-X pmid: 35114146

2 Smith R. The origins, development, and context of the Lancet Commission on the Value of Death. BMJ 2022;376:0277. doi: 10.1136/bmj.o277 pmid: 35105543

3 India P. Genesis. https://palliumindia.org/pallium-india/genesis 